\title{
Mobile Digital Devices and Preschoolers' Home Multiliteracy Practices
}

\author{
SUZANNA SO-HAR WONG \\ University of Alberta
}

\begin{abstract}
The increased use of digital devices such as touchscreen tablets in the home for work, communication, entertainment, and information searching makes them naturally attractive to toddlers and preschoolers who learn to communicate by observing and interacting with parents and older siblings. This paper presents one of the major findings from a study in Canada and Australia that examined preschoolers' (ages 3 to 5) home multiliteracy practices. By focusing on data from one of the participants in this study, this paper discusses how the use of iPad engages children in multimodal literacy practices, motivates literacy learning and provides opportunities for independent exploration and creation. This study is informed by complexity science and the data collected were analyzed using Green's $(1988,2012)$ three-dimensional model of literacy. The findings shed light on technology's evolving influence on society and contribute to insights in preschoolers' home literacy practices.
\end{abstract}

\section{"We shape our technologies and thereafter they shape us." (McLuhan, 1964)}

This paper presents the findings of one part of a yearlong qualitative study in western Canada and southern Australia that examined preschoolers' (3-5 years old) multiliteracy practices at home. This research was motivated by a belief that current literacy and communication practices are increasingly multimodal, employing images, music, writing, gesture, and speech. Research on contemporary multimodality (Jewitt, 2006; Jewitt \& Kress, 2003; Kress, 1997; Rowsell, 2013) suggests that the advancement of digital technologies "enable image, sound, and movement to enter the communicational landscape in new and significant ways" (Jewitt, 2009, p. 18). The new digital technologies with touch screen sensitivity and a variety of applications (apps) impact the ways children engage with multiliteracy practices at home. Young children use these new digital devices to communicate, learn, and to participate in and make sense of the world they live in (Marsh, 2011). In this study, the term "multiliteracy" refers to the New London Group's (1996) redefinition of texts and practices in their seminal document "A Pedagogy of Multiliteracies: Designing Social Future." Multiliteracies encompass multiple ways of meaning making and communicating, including visual, audio, spatial, behavioural, and gestural modes. Multimodal texts include the body-astext (New London Group, 1996, p. 64); preschoolers' bodies, therefore, are recognized as sign generating systems that enhance communication (Leander \& Boldt, 2012). The New London Group (1996) advocated a change of literacy perspective from the passive consumption of texts to the "understanding and enacting of literacy practices" (Leander \& Boldt, 2012, p. 2). Recent multiliteracy pedagogies (Cope \& Kalantzis, 2000, 2009; New London Group, 1996; Rowsell, 2013) can help us understand literacy as a dynamic 
and complex repertoire of social practices that help young children to participate in their everyday lives. Multiliteracies recognize digital technologies and other modalities (e.g. music, dance, visual representations) as valuable tools to support children's knowledge construction and meaning making (Rowsell, 2013). Here the term "multiliteracy practices" refers to children's reading and writing using printed and/or digital texts, viewing images, presenting ideas visually and orally, and the cultural ways children interact with literacy. Multiliteracy practices enable children to read and interpret texts that are mediated by multimodal and multimedia communicational tools.

\section{Digital Devices in Preschoolers' Lives}

Mobile touchscreen devices (e.g., iPads) provide opportunities for young children to engage with digital technologies in ways that previously were not possible. These digital technology tools enable young children to search the Internet for images, songs, and videos, and create digital pictures, audio recordings, video recordings, and other multimedia that can be uploaded and published in online platforms (Kucirkova, Messer, \& Sheehy, 2013; Plowman, Stevenson, Stephen, \& McPake, 2012). However, as Kucirkova et al. (2013) note, "a range of 'older' technologies, including audio-recorder, picture-camera, drawing pad, and an on-screen keyboard" (p. 115) have merged into one multifunctional and portable tool that enables young children who cannot yet read conventional print-based text to independently produce sophisticated digital texts (Lynch \& Redpath, 2014). Many contemporary preschoolers have access to these new digital devices. This has major implications for children's overall literacy development (Neumann \& Neumann, 2014), as their resources for learning and meaning making now include traditional print-based texts and "techno-literacy" (Marsh, 2004).

\section{Digital Devices and Early Literacy}

Studies of young children's use of digital technologies in the home confirm that young children engage in a wide range of digital literacy practices (Burke \& Marsh, 2013; Carrington \& Marsh, 2008; Flewitt, Messer, \& Kucirkova, 2014; Marsh, 2005; O'Mara \& Laidlaw, 2011; Pahl \& Rowsell, 2012). Digital technologies have become increasingly portable, affordable, and accessible to many young children at home in affluent societies such as Canada and Australia (Lynch \& Redpath, 2014; Rowsell, Saudelli, Scott, \& Bishop, 2013) and are increasingly available to children in developing countries (United Nations Educational Scientific and Cultural Organization, 2014). The portability of these new mobile touchscreen devices allows children to use them everywhere ${ }^{1}$ in their homes and communities. It is hardly surprising that many preschoolers are eager to master the use of these new technologies (Rideout, 2011).

Today, children under the age of nine years enjoy online activities; like adults, they watch videos, play games, search for information, and socialize in virtual worlds (Holloway, Green, \& Livingston, 2013). According to the Common Sense Media (2013) study of children in the United States, three-quarters (75\%) of the children (ages 0 to 8) studied had access to mobile digital devices such as tablets and smartphones at home ( $\mathrm{p}$. 9). A similar study conducted by Holloway et al. (2013) found an emerging trend in

\footnotetext{
${ }^{1}$ There are many iPad holders in the market for toddlers (e.g., iPad holders for baby car seat, toddler's toilet seat, and high chair). 
many European countries of toddlers and preschoolers using Internet connected devices such as tablets and smartphones for entertainment and communication (p. 4). As new digital devices continue to become an integral part of everyday life, young children increasingly incorporate them in their daily literacy practices by using them as play objects at home (Burke \& Marsh, 2013; Verenikina \& Kervin, 2011).

A growing body of research reveals that many children experience a digital technologies environment from a young age (Flewitt et al., 2014; Lynch \& Redpath, 2012; Marsh, 2011; Plowman et al., 2012; Rowsell et al., 2013). Many preschoolers are surrounded in their home environment by multimodal communication tools and digital media, including laptop computers, handheld and console video game players, and mobile touch screen devices such as smartphones and tablets (Common Sense Media, 2013; Holloway et al., 2013). This study examines the impact on young children's multiliteracy practices with digital devices, in particular the iPad, used in the home.

\section{Theoretical Orientation}

This study was informed by complexity thinking perspective on learning (Davis \& Sumara, 2008; Doll, 1993). Complexity thinking understands the world as an integrated whole, fundamentally interdependent, interconnected, and intertwined, rather than as an isolated and disconnected collection of small parts (Bateson, 1979; Capra, 1996; Maturana \& Varela, 1992). Therefore, complex phenomena-including young children's multiliteracy practices, their learning at home, and their interactions and relationships - needed to be viewed holistically and cannot be broken down into small parts. As Fenwick, Edwards, and Sawchuk (2011) remind us, in educational application of complexity thinking, "attention is drawn to the relationships among learners and environment" (p. 28). The interconnectedness of children and their home learning environment is a critical component of their complex learning systems.

Complexity thinking focuses on the study of complex systems that are pervasive in the world. Examples of complex systems are large-scale economies, climates, ecosystems, brains and living organisms. Complex thinking suggests that living organisms - human and cultural systems such as neighbourhood, schools, classrooms, families, and individual learners - might be better understood as adaptive, emergent, dynamic, and self-organizing (Doll, 1993; Waldrop, 1992). A learner in this case is a child; he or she is recognized as a complex learning system. A child as a complex learning system has the ability to self-organize and adapt within his or her learning environment. Self-organization within a complex system is sustained through a variety of feedback loops (Capra, 1996). "A "feedback loop" is a continuous and recursive process that takes part of a system's output and feeds it back as input" (Davis, Sumara, \& LuceKapler, 2008, p. 204). An example of a feedback is when parents communicate greater confidence in their child's abilities and selects literacy events and practices that are challenging but do-able. The parents' expectations support the child's willingness to accept the challenge independently. In turn, this feedback loop prompts the child to gain and internalize confidence that is first expressed by his or her parents. With the parents' feedback, young children's literacy development emerges from such recursive learning process. According to Thelen and Smith (1998), children's learning and development can be understood as "the multiple, mutual, and continuous interaction of all the levels of the developing system, from the molecular to the cultural" (p. 258). 
Complexity thinking provides theoretical principles for understanding the complex interrelations of children's early literacy learning at home. Recently, digital networks and technologies are frequently cited as examples of complexity thinking (Fenwick, Edwards, \& Sawchuk, 2011; Johnson, 1997, 2001, 2010); it also has been used to develop new practices and to support innovation in technology development (Johnson, 2010). Therefore, complexity thinking offers "new language" (Rorty, 1999) for thinking about the early literacy learning and multiliteracy practices of young children living in the "iWorld" (O'Mara \& Laidlaw, 2011).

\section{Conceptual Framework}

For this study, Green's $(1988,2012)$ three-dimensional (3D) model of literacy was used as an analytical tool to interpret the data at a microlevel and macrolevel. The model is rooted in many of the principles of complexity thinking: the learning processes of literacy are interconnected, nonlinear, dynamic, and recursive. Green (1988, 2012) suggested that literacy educators should view literacy holistically in terms of three interlocked dimensions: the operational, the cultural, and the critical. The three dimensions are not ordered or hierarchal, but work interdependently and should be integrated simultaneously to engage learners in purposeful literacy practices. They function recursively and can be conceptualized as nonlinear learning systems where constant changes and complex interactions are occurring (Green, 2012). With the changing demands for new literacies and technology learning, young children need to become proficient in nonlinear learning, constant change, and complex interactions of literacy and technology; for example, the reading path on a mobile touchscreen device is typically multidimensional and multimodal (Simpson, Walsh, \& Rowsell, 2013). Durrant and Green (2000) coined the term "l(IT)teracy" to highlight the importance of information technology (IT) in everyday literacy practices and to emphasize the merging of literacy and IT. Seeing literacy as multidimensional, with complex relationships, I could make new kinds of connections while examining the children's multiliteracy practices at home.

In the operational dimension, a child's "competency with regard to the language system" (Green, 2012, p. 5) is important. For instance, a participating preschooler's video production is an example of a child's competency with written language and visual meaning making in this dimension. The cultural dimension requires competency in the "meaning aspect of literacy" and requires competency with the meaning system in the culture (Green, 2012, p. 5). For example, children in my study playing online video games with virtual friends, communicating with grandparents in another city with Skype, ${ }^{2}$ or drawing pictures for family celebrations are engaging in the cultural dimension of literacy. In Green's critical dimension of literacy, the social construction of knowledge is achieved. To participate productively and effectively in social practices, young children must be socialized into the culture. In a digital learning environment, a child must be able to assess and critically evaluate software, websites, and other technology resources (Green \& Beavis, 2012). Green's 3D model of literacy pays attention to literacy and technology together, thus it provides a generative conceptual

\footnotetext{
${ }^{2}$ Skype is a software application that allows voice communication and video chat over the Internet.
} 
framework for researching young children's multiliteracy practices and recognizing the important role of digital cultural in young children's daily lives at home. In addition to its value as a framework for conceptualising children's home literacy practices, the model also "provides a lens for understanding digital texts and socially situated digital cultural practices in terms of literacy and technology" (Beavis, 2012, p. 128).

\section{Methodology}

This study was designed as a basic qualitative study (Merriam, 2009) using an ecological approach. This form of research is especially effective in studying the contexts in which young children live, learn, and grow at home (Naughton, Rolfe, \& SirajBlatchford, 2010). It is also one of the best ways in obtaining data about children's everyday activities and interactions within their natural environment (Hogan \& Greene, 2005; Naughton, Rolfe, \& Siraj-Blatchford, 2010). This study is grounded in the assumptions that reality is multilayered and complex. Many literacy events are not reducible to simple interpretation; therefore "thick descriptions" (Denzin \& Lincoln, 2005) are critical to represent children's complex multiliteracy practices at home. The methodology used in this study reflects my acknowledgement of the importance of incorporating the voices of young children, my complexity thinking perspective, my understanding of literacy practices in terms of thinking and cognition (Green, 2012), and literacy as social practices (Gee, 1996).

This study was conducted in seven homes in western Canada and four homes in southern Australia. The participants' homes contained a wide range of technology tools, including televisions, games consoles, desktop and laptop computers, DVD players, digital camera, and mobile touchscreen devices (such as tablets and smartphones), and every household had access to the Internet. The homes also had "traditional" literacy tools, like pencils and paper, crayons, chalks, paints, arts and craft materials and so on.

\section{Participants}

This study involved six Canadian and four Australian families whose 3-5 yearold children had not yet started formal schooling (i.e., Canadian kindergarten or Australian preparatory school) at the time of the study. The families were from diverse family backgrounds; five families were located in rural communities and five in urban centres. The families answered the recruitment posters in their communities or were recommended by families already recruited for the study. English was the primary language spoken at home, although in two Canadian families, several of the children were bilingual (i.e., they spoke French and English). Participant families included multigenerational, single-parent, and divorced-parent family compositions.

\section{Data Collection and Analysis}

During the initial visits to the potential participants' homes, I informally interviewed the families to determine if they met the criteria and the time demands for this study; that the young children had the oral language development and skills to communicate with me; and that the parents understood the importance of their presence during the home observations (i.e., that they could not leave the house and use my presence as a childcare opportunity). To indicate informed consent and assent, the parents signed both forms and returned them to me via email or I picked them up in-person. I 
asked many of the participating children to draw happy faces on the assent forms to indicate their willingness to participate in the study. My rapport with the children was strengthened by several informal visits and play-dates prior to my data collection. I gradually gained the trust of the children and families.

Many of the participating children took part in activities outside of their homes, including visits to museums or libraries, lessons (i.e., swimming, gymnastics, and circus acts), and invitations to play-dates with friends. To gain maximum access to the participants' homes, I implemented a flexible research schedule expressing a willingness to respond to last minute invitations to conduct interviews or observations in different times and places. My observations and interviews occurred at various times throughout the day, on average, once a week for one to four hours per observation; sometimes, the parents, children, and I prearranged the times. Some of the observations took place outside of the families' homes (e.g., at libraries, in neighbourhood playgrounds, community centres, museums), because the parents and children occasionally made unexpected decisions, or their decisions were made during the children's playtime.

The data collection tools used in this study were participant observations, informal interviews, field notes, and conversations with the children, as these tools were best suited to study young children's literacy practices in their natural home environment (Naughton et al., 2010). I acknowledge that my presence might have influenced some of the behaviours of the children and their family members because "observers always have some kind of impact on those they are observing" (Flewitt, 2006, p. 133). Several unexpected challenges emerged throughout the study. For example, during the informal children interviews, some participating parents had a tendency to answer their children's questions for them and occasionally they would interpret or contradict their children's answers. In several families, parent participants often inquired about their children's answers to my interview questions (e.g., "What did my son or daughter say about bedtime stories?"). These incidents became an ethical issue for me as a researcher. To respect my young participants' privacy, I could not reveal their answers to their parents. To avoid tensions with these parents, I learned to conduct informal interviews with the young participants when their parents were in another room and reassured the young participants that they did not have to answer all my interview questions. Another challenge was how to simultaneously video record, make field notes, participate in and observe the children's literacy practices, and listen to parents. To capture preschoolers' multiliteracy practices across a wide range of media-computers, television, DVDs, eBooks, picture books, comics, catalogues, magazines, and environmental prints - and document their everyday literacy practices in their natural home environment- I had one stationary video camera on a tripod for wide-angle recordings, one hand-held camera for close up recordings, and an audio recorder on a table for general voice recordings.

Video and audio recordings of home observations and interviews were transcribed, and field notes were juxtaposed with the video- and audio-recordings' transcripts. The raw data was coded after the transcripts and field notes were read several times. After the initial coding process, themes were created and critically, systematically and comparatively analyzed according to the research questions and issues identified in the literature. In this paper, I selected one exemplar in the form of a detailed research vignette to convey the essence of several themes that emerged in this study. 


\section{Parental Dispositions Toward Technologies}

Similar to the findings of Stephen, McPake, Plowman et al. (2008), I found that access to and use of technology tools at home was not dependent on socioeconomic status, family circumstances, or family composition; the technology tools that were available for children depended primarily on their parents' attitudes toward, dispositions, and interactions with technology tools at home. During the initial data analysis, the families were categorized into three groups:

- "New digital disposition" families and early adaptors of new technology tools: these were families that tended to have a wide range of technology tools for their children to use at home, with children and adults having their own digital devices. Typically, the parents in this group were enthusiastic and competent users of technology; they are often relaxed and comfortable about their children's independent use of technology tools at home and seldom monitor their children's screen time. Parents in this group tended to be opened to a "disorganized" or "messy" household, that is, their children did not have to "clean up" their games, toys, or dress-up clothes daily. For instance, a child could leave his Lego construction intact or incomplete puzzles and return to them later. Figure 1 shows a family's technology and traditional literacy tools in this category.

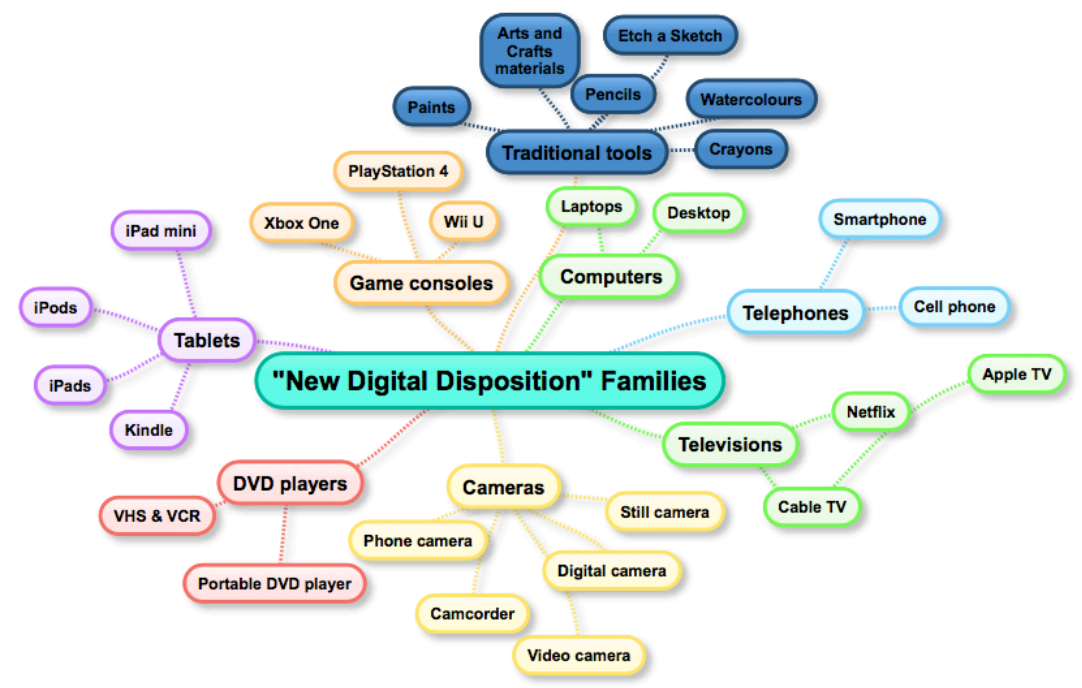

Figure 1. Technology tools available in a typical "new digital disposition" family.

- "New and old dispositions" families with mixed values of "traditional" literacy tools and new digital tools: these families tended to have a desktop and/or laptop computer, a television, a tablet, and/or a smartphone in the house for the whole family to use and share. The parents in this group sometimes supervised their children's use of technology tools closely and monitored their children's screen time at home. They often encouraged their children to explore both the traditional literacy tools and the new digital tools. The families in this group also had a large volume of traditional print-based books along with their digital reading and viewing materials at home. 
- "Traditional literacy disposition and willing to explore with new digital tools" families: these families tended to have one computer, a television, and a smartphone in the home, but children were not permitted to use them freely without parental supervision. The parents' attitudes toward technology tended to be guarded and parents often worried about the safety of their children using the Internet, however, they were willing to explore the affordances of new digital devices with their children together. Traditional print-based text and books were highly valued by parents in these homes.

Themes that emerged from each group were categorized and analyzed using Green's (1988, 2012) 3D literacy model and through a complexity thinking lens (Davis \& Sumara, 2008). One theme that emerged was that digital devices are impacting the ways preschoolers engage with multiliteracy practices at home. In the next section I present an example drawn from data gathered in this study to illustrate the ways a preschooler used digital devices in his daily home multiliteracy practices.

\section{The Participant}

Andrew (pseudonym) is a 5-year-old who lives with his parents and a 7-year-old sister in an urban centre of southern Australia. Andrew's parents are competent users of current digital devices; his father works in the information communication technology sector and his mother relies on technologies at work and at home. Each member of Andrew's household has an iPad with a secured password. Andrew is not yet literate in the traditional sense (i.e., he cannot read text or print his name with a pencil) but he can key in the letters of his name on the iPad and uses his name as an iPad password, and he can spell and recognize the word $\mathrm{Lego}^{\mathrm{TM}^{3}}$ in the search engines.

In Andrew's bedroom, there are books of many different genres (e.g. picture books, information books on Lego, comics, magazines, and junior novels), toys ranging from a lightsaber ${ }^{4}$ to Lego sets, dress-up clothes, musical instruments (e.g., drums, a guitar) and an iPad, which usually travels with him throughout the house. In the family's living room, there is a large bag full of Lego bricks and several elaborate Lego structures strewn on the floor. Andrew often takes photos of Lego structures with his iPad before he disassembles them. Lego structures built by Andrew, his sister, and their father are used to decorate the home (e.g., a Christmas manger created out of Lego bricks is sitting under the Christmas tree). Toys, digital objects such as his iPad, books, and musical instruments help Andrew make sense of the world because "literacy is embedded in 'things,' that is, objects, artifacts, the 'stuff' of life" (Pahl \& Rowsell, 2014, p. 164). Andrew took his iPad to his childcare centre to video record his play activities with his playmates, but the childcare worker disallowed further use of the iPad in the childcare centre. The following excerpt reveals how the iPad contributes to Andrew's motivation and independent learning in playful ways at home.

${ }^{3}$ Lego is a line of construction toys that consist of colourful interlocking plastic bricks.

${ }^{4}$ A lightsaber is a fictional energy weapon featured in the Star Wars universe. 
Vignette 1 Multimedia, Multimodal Devices and Motivation to Learn

Andrew is sitting in the living room surrounded by a brand new Lego building set $^{5}$. He opens the Lego set and begins to construct a Star Wars spaceship.

Andrew: $\quad$ This is what it looks like. (He points to the picture on the box. After a few minutes, his facial expression shows frustration.)

Andrew: $\quad$ What...? Where do these go? (He points to pieces of Lego bricks and compares his spaceship to the picture on the box. He reaches for the instructions pamphlet that comes with the Lego box and begins to examine the diagrams. With the instruction diagrams open, he tries to connect the Lego bricks together according to the diagram; see Figure 2.)

Andrew: No! This is not right! (He puts the "under construction" spaceship on the floor and runs to his bedroom to retrieve a book about Lego.)

Suzanna: Why are you using that book?

Andrew: $\quad$ There's a Starfighter in here. I remember it. (He flips through the pages of the book.)

Suzanna: What is a Starfighter?

Andrew: $\quad$ A spaceship with retractable landing gear. (He leaves the printed book page open, reaches for his iPad, scrolls through his YouTube videos playlist, taps on the video review of Starfighter, and begins to watch a video reviewing ${ }^{6}$ this new Lego set.)

Suzanna: $\quad$ Is that a movie on Lego?

Andrew: $\quad$ It's a Lego review ... it tells me about the Starfighter. (He pays close attention to the video presenter who appears to be a teenager.)

Suzanna: $\quad$ Why are you watching it?

Andrew: $\quad$ I want to make my own review. He is not very good. My dad can video me with my iPad tonight.

(Transcript from video recording, January 2013)

In analyzing the preceding vignette, it revealed that Andrew has demonstrated his competency in Green's operational dimension of literacy practices; he has a good understanding of the purposes of various kinds of language and texts (e.g., he uses conventional books, construction diagrams from his Lego sets, and digital texts in overlapping ways), an emerging understanding of conventional orthography (e.g., he can key in the letters of his name as a password, and type Lego in the search engine). Andrew is also competent in the critical dimension of literacy because he could tell me that a Lego reviewer was "not very good." As well, Andrew understands that a Lego reviewer must have some knowledge and expertise of the Lego set being reviewed. This indicates that Andrew is aware of the cultural dimension of literacy practices in the online Lego

\footnotetext{
${ }^{5}$ The Lego subculture encompasses books, movies, and online games.

${ }^{6}$ The Lego reviews Andrew watches are YouTube videos posted by Lego enthusiasts who share their ideas and opinions about certain Lego products. Users gather information on specific Lego sets by watching these videos.
} 
review community. During this interaction with multimedia and multimodal tools, Andrew has engaged and made meaning within all three dimensions of literacy practices simultaneously.

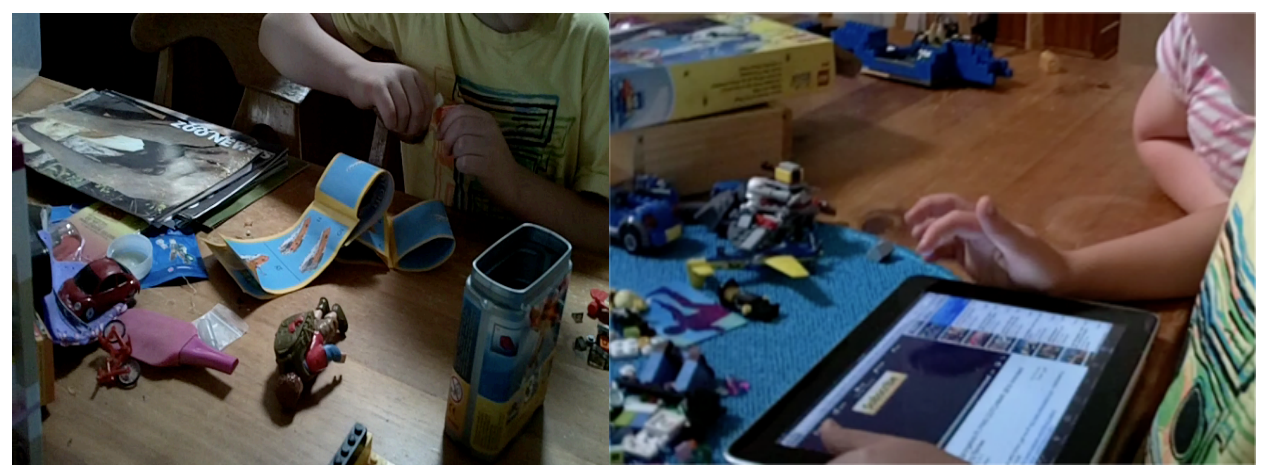

Figure 2. Watching Lego Reviews critically while constructing a Lego spaceship.

The preceding vignette also illustrated what Kress (2005) refers to as a new disposition to text. Whereas traditional disposition to text is stable, sequential, has linear order, is composed by the writer and interpreted by the reader, the new disposition to text is multimodal, radically unstable, designed by the producer, and redesigned by the reader (p. 3). Contemporary children often must apply the new disposition to text to achieve their goals (O'Mara \& Laidlaw, 2011). The iPad enables children to become producers and designers at a very young age. Andrew searches for information using a search engine and analyzes information on YouTube to help him produce a Lego construct. His multiliteracy practices are multilayered and often involved a recursive pattern.

I repeatedly noted that 5-year-old children like Andrew, who had limited traditional reading and writing skills, searched for information online with the assistance of the word prediction or completion feature ${ }^{7}$ on a search engine and they appeared to be confident with the results of their Internet searches (Wong, 2013). The new disposition to text seems to be a natural extension of preschoolers' oral language literacy learning practices. The flexibility and responsiveness of digital media offer very young children "hybridized" literacy practices (Marsh, 2011) that combine some of the characteristics of traditional literacy resources with the speed of new technoliteracies. That is, new technology tools afford new ways of working and playing with texts (Durrant \& Green, 2000) that are available in print and in digital form. Andrew's iPad clearly impacts his literacy practices, and his literacy development emerges in a recursive pattern.

\section{Vignette 2 - Developing Independence and Confidence}

The iPad affords opportunities for independent exploration and creation and can motivate children to learn traditional literacy skills that will enable them to utilize the iPad functionalities. The iPad can enable Andrew's independent attempt to create his own Lego review. He wants to video-record his own Lego review and to post it on YouTube. $\mathrm{He}$ asks his father to assist him in this video production by recording the video on a

\footnotetext{
${ }^{7}$ Word prediction or completion feature provided by many web browsers that predict the word or phrase a user wants to type in without the user actually typing it in completely. 
smartphone instead of on his iPad because he recognizes that it will be difficult to video record and demonstrate what his Lego structure can do at the same time. However, there is another reason to use his father's smartphone that he reveals in the following excerpt. He organizes his spaceship construction and mentally prepares the monologue that will be recorded in the video.

Suzanna: Why are you using your dad's iPhone to record?

Andrew: $\quad$ To upload it on YouTube.

Suzanna: $\quad$ What about your iPad? You can upload a video with your iPad.

Andrew: $\quad$ I am not allowed. I am a kid.

Suzanna: Why are you doing a review?

Andrew: $\quad$ The reviews are not very good! I want to post my own review because I love Lego. My review is short (most reviews are under 2 to 3 minutes).

Suzanna: Who do you think will watch your video?

Andrew: $\quad$ Everybody! Some grow-ups watch them too ... only good ones.

Suzanna: Really?

Andrew: $\quad Y e a h$, dad and I watch them all the time! (He smiles at his dad.)

(Transcript, 2013)

Andrew's father sets up his iPhone on a small tripod and begins to video record his son's Lego review. After several retakes, Andrew is unsatisfied with all of the recordings. He decides to rehearse his monologue some more before he tries again. From his insistence on improving his presentation, Andrew appears to understand the appropriate cultural dimension of literacy practices of the Lego review community on YouTube. He realizes he needs to make sure his review is concise, clear, and shows his expertise with this particular Lego set. The preceding vignette shows that Andrew is also aware of the rules for posting videos on YouTube channels. Andrew's venture into YouTube Lego reviews reveals that children's multiliteracy practices can involve Green's $(1988,2012)$ three dimensions of literacy practices simultaneously and holistically. His literacy learning and development were expanding in multiple directions and had many interacting components of a complex learning system.

Andrew's complex multiliteracy practices and learning processes matched well with the multiliteracy pedagogies of Cope \& Kalantzis (2009) and the New London Group (1996). He used digital technologies and other modalities (e.g., his Lego spaceship as visual representation, body gestures, oral storytelling) to support his construction of knowledge and meaning making (New London Group, 1996). Although Andrew cannot read or write in a traditional sense, he was able to share his experiences, knowledge, and interest to a large audience using his voice, Lego construction, and gesture in a video production (Kress, 1997). His home multiliteracy practices were interconnected and interrelated; they involved a new disposition to texts-embracing the combination of traditional and digital tools, print-based text, and digital text. Today's young children do not have to wait until they become fluent in reading and writing in the traditional sense before they engage in multiliteracy events. Their early experiences with multiliteracies and technologies at home play an important part in their development of literacy skills, communicative and creative competency (Marsh, 2011; Neumann \& Neumann, 2014; Pahl, 2006). In Andrew's home learning environment, he interacted with his parents, 
sister, toys, books, and online video games; new ideas often emerged within his multiliteracy practices.

\section{Discussion}

A growing body of research (Marsh, 2014; Rideout, 2013; Stephen, Stevenson, \& Adey, 2013) suggests that young children are incorporating digital devices such as tablets and smartphones in their home literacy practices. New technologies and new forms of literacy practices are wide spread in many children's homes such as Andrew's household. The portability of tablets and their touchscreen responsive interface make them accessible; that encourages young children to explore their own creations and productions with some assistance from parents or older siblings.

The increased use of digital devices in the home for work, communication, entertainment, and information searching makes them naturally attractive to toddlers and preschoolers who learn to communicate by observing and interacting with parents and older siblings. The vignettes presented in this paper depict a shift in the home literacy practices of a contemporary young child who is coming under the influence of new technology tools. In this example, a child's parents intentionally scaffold his early literacy learning and development by encouraging him to engage in multimodal and multimedia activities at home, in addition to providing traditionally dominant print-based text. Furthermore, the online experience taught the child the etiquette expected of a member of an online community.

The study examines the range of multiliteracy practices that young children engage in at home. The combination of technoliteracy and traditional print-based literacy competencies I observed some children developing over the course of the research will be of great value when they start formal schooling. Through complex interactions with multiliteracy practices at home, many of the preschoolers are gaining knowledge in the operational, cultural, and critical dimensions of literacy. I suggest that connections between home and school multiliteracy practices can be strengthened by recognizing that children are learning valuable literacy skills and are gaining knowledge about their world through multimodal tools. These young children will have a wide range of knowledge related to multiliteracy practices when they begin formal schooling. Early childhood educators need to acknowledge, accept, and value the "funds of knowledge" (Moll, Amanti, Neff, \& Gonzalá, 2005) these young children bring with them when they enter formal schooling. The insights gained in this study can inform early childhood educators and help them to plan literacy practices that recognize the expanded expertise of modern multiliterate preschoolers. If formal school learning is to build on the experiences and strengths that young children bring to early childhood education settings, then, how can what is happening at home be bridged to school practices using technologies with literacy?

\section{References}

Bateson, G. (1979). Mind and nature: A necessary unity. New York: Dutton.

Beavis, C. (2012). Digital games, new literacies and English. In B. Green \& C. Beavis

(Eds.), Literacy in 3D: An intergrated perspective in theory and practice.

Camberwell, VIC: ACER. 
Burke, A., \& Marsh, J. (2013). The changing landscapes of children's play worlds. In A. Burke \& J. Marsh (Eds.), Children's virtual play worlds: Culture, learning, and participation (Vol. 58, pp. 1-10). New York, NY: Peter Lang.

Capra, F. (1996). The web of life: A new scientific understanding of living systems. New York, NY: Anchor Books.

Carrington, V., \& Marsh, J. (2008). Forms of literacy. Beyond current horizons:

Technology, children, schools and families. Retrieved from

http://www.beyondcurrenthorizons.org.uk/forms-of-literacy

Common Sense Media. (2013). Zero to eight: Children's media use in America 2013. Program for the study of children and media. Author.

Cope, B., \& Kalantzis, M. (2000). Multiliteracies: Literacy, learning and the design of social futures. Melborne, Australia: Macmillan.

Cope, B., \& Kalantzis, M. (2009). "Multiliteracies": New literacies, new learning. Pedagogies: An International Journal, 4, 164-195.

doi:10.1080/15544800903076044

Davis, B., \& Sumara, D. (2008). Complexity as a theory of education. Transnational Curriculum Inquiry, 5(2), 33-44.

Davis, B., Sumara, D., \& Luce-Kapler, R. (2008). Engaging minds: Changing teaching in complex times $\left(2^{\text {nd }}\right.$ ed). New York: Routledge.

Denzin, N., \& Lincoln, Y. (2005). The SAGE handbook of qualitative research ( $3^{\text {rd }}$ ed.). Thousand Oaks, CA: SAGE.

Doll, W. (1993). A post-modern perspective on curriculum. New York: Teachers College Press.

Durrant, C., \& Green, B. (2000). Literacy and the new technologies in school education: Meeting the L(IT)eracy challenge? Australian Journal of Language and Literacy, 23(2), 89-108..

Fenwick, T., Edwards, R., \& Sawchuk, P. (2011). Emerging approaches to educational research: Tracing the sociomaterial. New York: Routledge.

Flewitt, R. (2006). Using video to investigate preschool classroom interaction: Education research assumptions and methodological practices. Visual Communication, 5(1), 25-50. doi: 10.1177/1470357206060917

Flewitt, R., Messer, D., \& Kucirkova, N. (2014). New directions for early literacy in a digital age: The iPad. Journal of Early Childhood Literacy.

doi:10.1177/1468798414533560

Gee, J. (1996). Socila linguistics and literacies: Ideology in discourses. New York: Falmer.

Green, B. (1988). Subject-specific literacy and school learning: A focus on writing. Australian Journal of Education, 32(2).

Green, B. (2012). Subject-specific literacy and school learning: A revised account. In B. Green \& C. Beavis (Eds.), Literacy in 3D: An integrated perspective in theory and practice (pp. 2-21). Camberwell, VIC: ACER.

Green, B., \& Beavis, C. (2012). Literacy in 3D: An integrated perspective in theory and practice, . Camberwell, VIC: ACER.

Hogan, D., \& Greene, S. (2005). Researching Children's Experience : Methods and Approaches. London: SAGE. 
Holloway, D., Green, L., \& Livingston, S. (2013). Zero to eight. Young childreh and their internet use. London: LSL.

Jewitt, C. (2006). Multimodality, "reading", and "writing" for the 21 st Century. Discourse: Studies in the Cultural Politics of education, 26(3), 315-331.

Jewitt, C. (2009). An introduction to multimodality. In C. Jewitt (Ed.), The Routledge handbook of multimodal analysis (pp. 14-27). Oxon: Routledge.

Jewitt, C., \& Kress, G. (2003). Multimodal literacy. New York: Peter Lang.

Johnson, S. (1997). Interface culture: How new technology changes the way we create and communicate. New York: Basic Books.

Johnson, S. (2001). Emergence: The connected lives of ants, brains, cities, and software. New York: Scribner.

Johnson, S. (2010). Where good ideas come from: The natural history of innovation. New York: Riverhead Books.

Kress, G. (1997). Before writing: Rethinking the paths to literacy. London, UK: Routledge.

Kress, G. (2005). Communication now and in the future. Discussion paper for the English 21 Project: United Kingdom Qualifications and Curriculum Authority.

Kucirkova, N., Messer, D., \& Sheehy, K. (2013). Sharing personalised stories on iPads: A close look at one parent-child interaction. Literacy - UKLA, 47(3), 115-122.

Leander, K., \& Boldt, G. (2012). Rereading “A Pedagogy of Multiliteracies": Bodies, texts, and emergence. Journal of Literacy Research. doi: $10.1177 / 1086296 \times 12468587$

Lynch, J., \& Redpath, T. (2012). 'Smart' technologies in early years literacy education: A meta-narrative of paradigmatic tensions in iPad use in an Australian preparatory classroom. Journal of Early Childhood Literacy, 1-28. doi:10.1177/1468798412453150

Lynch, J., \& Redpath, T. (2014). 'Smart' technologies in early years literacy education: A meta-narrative of paradigmatic tensions in iPad use in an Australian preparatory classroom. Journal of Early Childhood Literacy, 14(2), 147-174. doi:10.1177/1468798412453150

Marsh, J. (2004). The techno-literacy practices of young children. Journal of Early Childhood Research, 2(1), 51-66. doi: 10.1177/1476718X0421003

Marsh, J. (2005). Popular culture, new media and digital literacy in early childhood (pp. xiii, 245 p.). Retrieved from http://www.netLibrary.com/urlapi.asp?action=summary\&v=1\&bookid=102926

Marsh, J. (2011). Young children's literacy practices in a virtual world: Establishing an online interaction order. Reading Research Quarterly, 46(2).

Marsh, J. (2014). Researching young children's literacy practices in online virtual worlds. In P. Albers, T. Holbrook \& A. Flint (Eds.), New methods of literacy research (pp. 196-209). New York, NY: Routledge.

Maturana, H., \& Varela, F. (1992). The tree of knowledge: The biological roots of human understanding. Boston, MA: Shambhala.

McLuhan, M. (1964). Understanding media: The extensions of man. London: Routledge and Kegan Paul.

Merriam, S. (2009). Qualitative research: A guide to design and implementation. San Francisco, CA: Jossey-Bass. 
Moll, L., Amanti, C., Neff, D., \& Gonzaláz, N. (2005). Funds of knowledge for teaching: Using a qualitative approach to connect homes and classrooms. Mahwah, NJ: Lawrence Erlbaum.

Naughton, G., Rolfe, S., \& Siraj-Blatchford, I. (2010). Doing early childhood research: International perspectives on theory and practice. New York, NY: McGraw-Hill.

New London Group. (1996). A pedagogy of multiliteracies: Designing social futures. In B. C. M. Kalantzis (Ed.), Multiliteracies: Literacy learning and the design of social futures (pp. 9-37). New York: Routledge.

Neumann, M., \& Neumann, D. (2014). Touch screen tablets and emergent literacy. Early Childhood Education Journal, 42(4), 231-239.

O'Mara, J., \& Laidlaw, L. (2011). Living in the iWorld: Two literacy researchers reflect on the changing texts and literacy practices of childhood. English Teaching: Practice and Critique, 10(4), 149-159.

Pahl, K. (2006). Family literacy goes to school. Afterword. In J. Rowsell (Ed.), Family literacy: Bridging home and school (pp. 254-258). Markham, ON: Pembroke.

Pahl, K., \& Rowsell, J. (2012). Literacy and Education: Understanding the new literacy studies in the classroom. Los Angeles, CA: SAGE.

Pahl, K., \& Rowsell, J. (2014). Artifactual literacies. In P. Albers, T. Holbrook \& A. Flint (Eds.), New methods of literacy research (pp. 163-176). New York: Routledge.

Plowman, L., Stevenson, O., Stephen, C., \& McPake, J. (2012). Preschool children's learning with technology at home. Computers \& Education, 59, 30-37. doi:10.1016/j.compedu.2011.11.014

Rideout, V. J. (2011). Zero to eight: Children's media use in America. A Common Sense Media Research Study. San Francisco, CA: Common Sense Media.

Rideout, V. J. (2013). Zero to eight: Children's media use in America 2013. Program for the study of children and media: Common Sense Media.

Rorty, R. (1999). Philosophy and social hope. New York: Penguin Books.

Rowsell, J. (2013). Working with multimodality: Rethinking literacy in a digital age. New York: Routledge.

Rowsell, J., Saudelli, M., Scott, R., \& Bishop, A. (2013). iPads as placed resources: Forging community in online and offline spaces. Language Arts, 90(5), 351-360.

Simpson, A., Walsh, W., \& Rowsell, J. (2013). The digital reading path: researching modes and multidirectionality with iPads. Literacy, 47(3), 123-129.

Stephen, C., McPake, J., Plowman, L., \& Berch-Heyman, S. (2008). Learning from the children: Exploring preschool children's encounters with ICT at home. Journal of Early Childhood Research, 6(2), 99-117.

Stephen, C., Stevenson, O., \& Adey, C. (2013). Young children engaging with technologies at home: The influence of family context. Journal of Early Childhood Research, 11(2), 149-164. doi: 10.1177/1476718x12466215

Thelen, E., \& Smith, L. (1998). Dynamic systems theories. In W. Damon \& R. Lerner (Eds.), Handbook of child psychology (5th ed., Vol. 1, pp. 563-634). New York: John Wiley \& Sons.

United Nations Educational Scientific and Cultural Organization. (2014). Reading in the mobile era: A study of mobile reading in developing countries. France: UNESCO.

Verenikina, I., \& Kervin, L. (2011). iPads, digital play and preschoolers. He Kupu, 2(5), 4-19. 
Waldrop, M. (1992). Complexity: The emerging science at the edge of order and chaos. New York: Touchstone Books.

Wong, S. (2013). Hop on Pop, click on Poptropica: Preschoolers' multiliteracy practices at home. Early Childhood Education Journal of Alberta Teachers Association, 41(1), 25-30.

Author Biography

Suzanna So-Har Wong is currently completing her PhD in elementary education, at the University of Alberta, with a focus on language and early literacy. Her research interests are early literacy development, digital literacies, and multiliteracy learning and using current technology tools, particularly the mobile touch screen devices. 